\title{
Notas sobre o trabalho de mulheres tecelãs: brasileiras no fio da invisibilidade
}

\author{
Amanda Motta Angelo Castro ${ }^{1}$, Edla Eggert ${ }^{2}$
}

\begin{abstract}
Resumo
Esse artigo busca situar, historicamente, a tecelagem e apresentar algumas reflexões sobre o trabalho artesanal de tecelãs, decorrentes de pesquisa empírica ocorrida em um ateliê de tecelagem em Alvorada, região metropolitana de Porto Alegre, Rio Grande do Sul, Brasil, visando a problematização do cotidiano do trabalho de mulheres tecelãs e sua (in)visibilidade social. Observamos que o trabalho artesanal possui técnica, arte e saberes. Contudo, mesmo com a sua riqueza artística e tecnológica, este trabalho não é socialmente visibilizado. Com o viés do feminismo e da educação popular, buscamos avaliar o porquê do trabalho destas mulheres ser (in)visibilizado. A metodologia constituiu-se de observação participante e entrevistas individuais e teve como base o conhecimento feminista. Portanto, uma epistemologia feminista, visando trabalhar, sobretudo, com base nos estudos que vêm sendo produzidos e problematizados por feministas no Brasil e na América Latina.
\end{abstract}

\section{Palavras-chave}

Feminismo. Educação Popular. Tecelagem Manual. Mulheres.

1. Doutoranda em Educação na Universidade do Vale do Rio dos Sinos, bolsista CAPES, professora no Instituto Federal Sul-Rio-Grandense na área de Pedagogia. E-mail: motta.amanda@terra.com.br.

2. Doutora em Teologia pela Escola Superior de Teologia, professora e coordenadora do Programa de PósGraduação em Educação da Universidade do Vale do Rio dos Sinos. E-mail: edla@unisinos.br. 


\title{
Notes on the work of weaver women: brazilian women on the string of invisibility
}

Amanda Motta Angelo Castro*, Edla Eggert**

\begin{abstract}
This article seeks to situate weaving, historically, and present some reflections about handcraft work of weaver women based on our empirical research which took place at a weaving atelier in Alvorada, metropolitan zone of Porto Alegre, Rio Grande do Sul, Brazil. Aims at problematizing the everyday lifework of women weavers and their social (in)visibility. We observed that handcraft work possesses technique, art and knowledge. However, even in its artistic and technologic richness, this work is not socially made visible. Through feminism and popular education, we seek to analyze because is the work of these women made (in) visible. The methodology of this research had participant observation, individual interviews and was based on Feminist knowledge; therefore, a Feminist epistemology, aiming at working, above all, with studies which have been produced and problematized by Feminists in Brazil and throughout Latin America.
\end{abstract}

\section{Keywords}

Feminist Studies. Popular Education. Manual Weaving. Women.

\footnotetext{
* Candidate for a doctor's degree in Education at the University of Vale do Rio dos Sinos, CAPES scholar, professor at Instituto Federal Sul-Rio-Grandense in the área of Pedagogy. E-mail: motta.amanda@terra.com.br.

**Doctor in Theology at the Techonology and Management School, professor and coordinator of pos- graduate programs of education at the University of Vale do Rio dos Sinos. E-mail: edla@unisinos.br.
} 


\section{Introdução}

\section{A pesquisa em educação tramada em um ateliê}

$\begin{array}{ccccc}\text { Nossa pesquisa } & \text { permeou um } \\ \text { espaço específico em que fios são }\end{array}$ tramados no cotidiano de um ateliê de tecelagem, por meio de uma arte milenar desenvolvida até os dias atuais: a tecelagem.

A empiria, segundo Hilton Japiassú ${ }^{3}$ e Danilo Marcondes (2006), é uma experiência bruta que vem antes de qualquer elaboração no campo do conhecimento. A empiria constitui, portanto, o que vem antes da intervenção racional, da fundamentação teórica e da sistematização. Neste artigo, temos, portanto, uma pesquisa empírica que ocorreu em um ateliê ${ }^{4}$ de tecelagem.

A pesquisa tem vida, ela é uma forma de pronunciar o mundo, de partilhar o saber (BRANDÃO; STRECK, 2006). Compreendemos que a pesquisa não é neutra (FREIRE, 1999) e, por esse motivo, entendemos ser importante e necessário situarmos o campo teórico a partir do qual refletimos.

Utilizamos o conceito de gênero como o estudo das relações socialmente produzidas de homens com mulheres, mulheres entre mulheres e homens entre homens, um conceito que foi sendo produzido nos estudos relacionados a diversos campos do feminismo, por isso também de ordem ideológica, política e de lutas. Lutas que visam à transformação das relações entre todos, mulheres com homens, mulheres entre si e também homens entre si (SAFFIOTI, 2004).

Nossa pesquisa ocorreu em Alvorada, município da região metropolitana de Porto Alegre, no Rio Grande do Sul, onde o referido ateliê está localizado. Alvorada ${ }^{5}$ emancipou-se no dia 17 de setembro de 1965, conforme a Lei Estadual no 5026. Acredita-se que o nome da cidade seja uma referência ao seu povo, constituído, em sua maioria, por trabalhadores que acordavam nas primeiras horas da manhã para trabalhar na capital Porto Alegre. Com 72,9 km2, e área urbana legal de 52 km2, o município é um dos menores do Estado e sua economia é baseada, principalmente, no comércio e no setor de serviços. A maioria da população trabalha em Porto Alegre, fazendo com que Alvorada seja conhecida como cidadedormitório. Sua população, segundo dados do IBGE de 2008, é de 211.233 habitantes.

No período 1991-2000, o Índice de Desenvolvimento Humano (IDH) de Alvorada cresceu $7,26 \%$ e passou de 0,716 para 0,768 em 2000, de acordo com a classificação do Programa das Nações Unidas para o Desenvolvimento (PNUD). O crescimento do IDH de Alvorada, segundo o PNUD, ocorreu, principalmente, por meio da educação. Para atender à população, Alvorada possui, hoje, 57 estabelecimentos de ensino públicos e privados, sendo 45 de ensino infantil e fundamental, 11 de ensino médio

3. Utilizaremos o nome e sobrenome do/a autor/ar na primeira citação. Nas citações seguintes, os/as autores/ as passam então a ser mencionados apenas com o último sobrenome. Seguimos essa orientação como uma forma inclusiva de perceber a produção científica. Paulo Freire faz referência à importância do lugar da linguagem inclusiva após ser criticado por sua linguagem machista por feministas norte-americanas que leram sua principal obra - Pedagogia do Oprimido (1964). Freire admite seu machismo e retoma esta questão na Pedagogia da Esperança, publicada em 1992, passando, então, a utilizar uma linguagem inclusiva.

4. Segundo a enciclopédia livre, um estúdio ou ateliê é o lugar de trabalho de pessoas com vontade de criar e onde se pode experimentar, manipular e produzir um ou mais tipos de arte. O termo francês para estúdio, atelier, além de designar um estúdio artístico, é utilizado para caracterizar o estúdio de um designer de moda ou mesmo artesão.

5. As informações obtidas sobre Alvorada encontram-se disponíveis em: <http://www.alvorada.rs.gov.br>. Acesso em: 8 out. 2009. 
e um de ensino superior (privado). $\mathrm{Na}$ área da saúde, o município conta com um hospital público e mais 34 estabelecimentos de saúde entre públicos e privados $^{6}$. Para melhor apresentar o lugar que pesquisamos, faremos uma descrição do local. Após sairmos de Porto Alegre, de ônibus, levamos em torno de 50 minutos para chegar até Alvorada (de carro o trajeto tem duração de aproximadamente 30 minutos). Chegamos à avenida principal da cidade e, em aproximadamente 10 minutos, chegamos ao ateliê. Uma pequena casa de madeira com cinco cômodos, sendo um para o tingimento dos fios, um para guardar as peças prontas, uma pequena cozinha - onde as mulheres reúnemse pela manhã e à tarde para o cafezinho - um cômodo para guardar os fios e outro, onde estão os teares pequenos (os teares maiores ficam ao longo do quintal). O espaço do ateliê parece bem precário, mas não há dúvida de que o lugar possui uma "boniteza". Durante o trabalho, era possível ouvir os passarinhos cantando, abrigados por muitas árvores ao redor do quintal, as quais fazem sombra para o ateliê. Por vezes, quando chove, ao chegar ao portão, podemos sentir o cheiro bom de terra molhada.

Neste lugar, mulheres "ganham a vida" fazendo arte, entre tramas e fios, uma arte milenar. A tecelagem é uma das formas mais antigas de artesanato presente nos dias atuais. No ateliê, os fios e tramas ganham forma e cores em um processo de criação e produção encantador.

No final do ano de 2010, no cotidiano do ateliê, trabalhavam sete mulheres tecelãs, de segunda a sexta, em turno integral, das $8 \mathrm{~h}$ às $18 \mathrm{~h}$, produzindo peças de vestuário feminino e produtos para casa. Para realizar o trabalho, as mulheres estavam organizadas em uma cooperativa ${ }^{7}$.

O cooperativismo representa a união entre pessoas voltadas para um objetivo em comum. Uma organização desta natureza caracteriza-se por ser gerida de forma democrática e participativa, de acordo com aquilo que pretendem seus associados (BRASIL, 1971). As sociedades cooperativas estão reguladas pela Lei no 5.764 de 1971, que definiu a Política Nacional de Cooperativismo.

Há poucas opções de trabalho na cidade. Sendo assim, para evitarem o longo trajeto de deslocamento até a capital (onde muitas mulheres de Alvorada trabalham, sobretudo nas atividades do comércio, serviços gerais e em casas de família como empregadas domésticas), algumas trabalhadoras buscaram na tecelagem uma forma de sustento, tanto para elas como para suas famílias, visto que várias delas são chefes de família.

\section{Metodologia}

É importante salientar que a metodologia utilizada na pesquisa também aponta nosso compromisso com o feminismo, sendo, portanto, uma metodologia de mudança e transformação:

O compromisso de uma metodologia de pesquisa feminista é conseguir perceber na "outra" pesquisada uma cúmplice da descoberta de nós mesmas. Somos sujeitos capazes de transformar determinada realidade/pesquisa e nos transformarmos. A pesquisa feminista identifica propositalmente a relação sujeito-sujeito como sendo o elo diferencial das demais posturas neutralizantes na pesquisa (EGGERT, 2003, p. 20).

Entendemos que a pesquisa que originou este artigo e as metodologias que foram utilizadas

6. Informações disponíveis em: <http://www.alvorada.rs.gov.br/>.Acesso em: 5 jun. 2009.

7. Salientamos que, embora as mulheres do ateliê estejam organizadas por meio de uma cooperativa, o cooperativismo não será tema da nossa pesquisa. Entendemos ser pertinente o esclarecimento de que não será trabalhada aqui a questão do cooperativismo, visto que este é um campo acadêmico consolidado com pesquisas importantes sobre o tema. 
deixaram marcas em ambas: nas mulheres pesquisadas e em nós mesmas. A pesquisa ocorreu por meio da observação participante e entrevistas que buscaram resgatar as histórias de vida das mulheres pesquisadas.

Consideramos que uma boa ciência é feita com uma boa observação e registro. A observação participante foi a metodologia mais usada na pesquisa e permeou todos os momentos da mesma. Durante um ano, nossa presença foi constante no ateliê, observando, ajudando as mulheres no que sabíamos fazer, aprendendo a tecer com elas. Tivemos conversas informais na sala de produção, fotografias e filmagens. Após um dia de observação, era feito o registro no diário de pesquisa.

É importante ressaltar que a observação participante, muito desenvolvida pela Antropologia, foi retomada pela educação popular. Na área da Educação, podemos citar os estudos por Carlos Rodrigues Brandão (2003). Tal metodologia nos levou a partilhar do cotidiano e nos abriu outras opções metodológicas, isso porque,

A observação participante, que obriga à partilha da vida do/com o outro e que nos envolve e faz se completarem estratégias (ou técnicas, se quiserem) de coleta de dados, como registro etnográfico em diários de campo, a entrevista, a história de vida, a exegese do visto e do ouvido [...] (BRANDÃO, 2003, p. 293).

Durante nossa pesquisa, por meio da observação, participamos envolvendonos no cotidiano do ateliê. Sem dúvida, esses momentos foram extremamente ricos para que, mais tarde, pudéssemos escrever sobre nossa partilha. Portanto, a dissertação que deu origem a este artigo foi escrita com partilha, na medida em que pesquisávamos e éramos, a princípio, "as estranhas" no grupo. As mulheres nos acolheram e ali estávamos na prática, afirmando os escritos de Paulo Freire
(2006), que nos ensinou que não há saberes maiores, que temos saberes diferentes, mas não mais importante que qualquer outro. Segundo Augusto Triviños (1987) e Alda Judith Alves-Mazzotti e Fernando Gewandsznajder (1998), a observação participante envolve três etapas: aproximação da instituição e estabelecimento de vínculos; realização da observação no contexto dos sujeitos para a coleta de dados; registro posterior aos acontecimentos ocorridos durante a observação, como comportamentos, ações e diálogos observados.

De acordo com Brandão (2003), a pesquisa requer partilha. Por esse motivo, acompanhamos o cotidiano do ateliê, participamos do grupo de oração no início dos trabalhos, do momento "devocional", das conversas sobre tecelagem, família e vida. Por meio dessa metodologia, coletamos material durante as observações participantes realizadas no ateliê no período de 2009 e 2010.

A entrevista individual, muito utilizada em pesquisas qualitativas, também foi necessária. Para Rosália Duarte (2004), entrevistas são fundamentais, quando se precisa/deseja mapear práticas, crenças e valores. Diante disso, entendemos que a entrevista foi fundamental.

Sabemos que a entrevista requer que sejamos boas entrevistadoras para que, de fato, tenhamos possibilidade não apenas de ouvir, mas de escutar de forma ativa e atenta, demonstrar interesse na fala da entrevistada e participar da entrevista com gestos que façam com que a entrevistada perceba que suas palavras estão recebendo atenção. Sobre isso, José Magnani (1986, p. 23) destaca:

\footnotetext{
Além de ouvir, o pesquisador precisa ficar atento às expressões utilizadas pelo entrevistado, pois ele pode simular palavras e conceitos que não são utilizados no seu dia a dia, tentando mostrar aquilo que ele acha que o entrevistador quer ouvir. É por isto que nem tudo deve ser entendido como verdade,
} 
mas pode e deve ser analisado frente aos demais discursos e conceitos que embasam o trabalho.

Entendemos que a observação participante no ateliêfoiumelementofacilitadorpara a realização das entrevistas. Como estávamos constantemente naquele espaço, nossa aproximação junto às mulheres foi um fator fundamental para que elas pudessem falar conosco. Assim, as narrativas femininas foram coletadas ora nas observações participantes, ora no momento das entrevistas.

\section{Epistemologia feminista e a pesquisa com mulheres}

A epistemologia tradicional, exercida pelas instituições formais de ensino, busca em alguma medida processar e filtrar o conhecimento. O feminismo e a educação popular têm denunciado e alertado sobre a supergeneralização (GEBARA, 2008) e os projetos pedagógicos hegemônicos (STRECK, 2010), ressaltando que os valores, as experiências, os objetivos e as interpretações dos grupos dominantes são apenas valores, experiências, objetivos e interpretações desses grupos e não da humanidade como um todo.

Ivone Gebara (2008, p. 32) afirma a respeito desta supergeneralização:

Sem dúvida, o conhecimento produzido por uma elite a serviço dos detentores do poder é mais valorizado do que qualquer outro produzido, por exemplo, por um grupo de catadores de lixo. Não só a questão das classes sociais aparece de forma marcante em todos os processos epistemológicos, mas também a questão da raça, do gênero, das idades, e da orientação sexual. Nossa maneira de expressar nosso conhecimento do mundo é reveladora de nosso lugar social e cultural. E este lugar condiciona nossa confiança e desconfiança, nossa valoração maior ou menos em relação ao que proposto como conhecimento.
Portanto, foi a partir das questões de classe social, gênero, raça, etnia, entre outras, que surgiu uma área da epistemologia dedicada a compreender a forma como o gênero influencia aquelas concepções e práticas e como elas têm sistematicamente colocado em desvantagem as mulheres e outros grupos subordinados.

Gebara (2008) argumenta em favor de uma "epistemologia da vida ordinária", que busca, a partir do cotidiano, da vida das pessoas comuns, mostrar outras formas de conhecimento tecidas no dia a dia. Segundo a autora, a epistemologia da vida ordinária é a epistemologia de todos e todas nós, de quem é mortal. Entender e filtrar os conhecimentos ordinários produzidos à margem das instituições formais tem sido, até hoje, uma luta constante para a epistemologia feminista. Por muito tempo, as mulheres foram por elas mesmas esquecidas e, por consequência, também pela Academia (EGGERT, 2008).

Tais aspectos nos conduzem a afirmar que pesquisar mulheres, em uma perspectiva feminista é desafiar uma lógica dominante de um mundo hierárquico e patriarcal (GEBARA, 2000; 2008). A pesquisa com mulheres requer algumas abordagens peculiares, para além da epistemologia reflexiva ou científica. Aqui, pensamose sabemosque nãose podeabandonar, de forma alguma a epistemologia científica. Entretanto, precisamos de novas alternativas.

O olhar epistemológico feminista, tanto ordinário como científico, permite reler a história, e, sem sombra de dúvida, os resultados das inúmeras perspectivas abertas têm sido dos mais criativos e instigantes. A epistemologia feminista aponta, sobretudo como fonte principal, a experiência, aquela tecida no cotidiano (PEREIRA, 2003), e, por isso, experiências invisibilizadas (CASTRO; BECKER; EGGERT et al., 2010) e experiências negligenciadas.

O feminismo e a educação popular apontam a importância da experiência, pois ambos a consideram como desencadeadora da produção do conhecimento. Por esse 
motivo, o conceito de experiência - ainda em construção - tem para as mulheres de nossa pesquisa um investimento de estudo e debate.

Precisamos dar conta dos processos históricos que, através dos discursos, posicionam sujeitos que produzem suas experiências. Não são os indivíduos que têm experiências, mas os sujeitos são constituídos através da experiência. A experiência torna-se não a origem de nossa explicação, não a evidencia autorizada que fundamenta o conhecimento, mas sim aquilo que buscamos explicar, aquilo sobre o qual se produz conhecimento (SCOTT, 1999, p. 27)

Sabemos que mulheres possuem uma experiência histórica e cultural diferenciada da masculina, uma experiência que, muitas vezes, está "às margens". Isso acontece porque, conforme referido anteriormente, essas experiências são do cotidiano ordinário, tecidas em conversas informais, nos espaços privados e do lar. Entretanto, nessas margens encontramos experiências cruciais para a pesquisa com mulheres, o que nos leva a valorizar o conceito de experiência. Sobre isso, Eggert(2010, p. 7) afirma:

A apreensão da realidade é o retorno ao ateórico, ou seja, o nível da experiência. Nesse sentido, desde a década de setenta, as feministas tinham muita consciência da importância da experiência na luta pela defesa da liberdade e equidade na vida das mulheres. A questão é transformar a experiência do cotidiano e das lutas em teoria não só para traduzi-las, mas para abrangê-las.

Percebemos que dar destaque ao conhecimento ateórico, tecido em espaços do cotidiano, de onde surge a experiência das mulheres, tem sido uma luta feminista desde seu início, sobretudo no que tange a trazê-las como conhecimento.

A epistemologia feminista vem rompendo paradigmas estabelecidos, descobrindo e redescobrindo a vida e a produção das mulheres ao longo da história e de tantas outras que hoje fazem histórias e produzem, como as mulheres de nossa pesquisa. Em alguma medida, tentamos fazer com que suas produções saiam da invisibilidade, que se percebam como atuantes em sua própria história, porque ela não está dada (FREIRE, 1999).

Essa busca por algo que precisa ser construído - e que é de nossa responsabilidade - requer alguns instrumentos, como afirma Eggert (2009, p. 32)

\begin{abstract}
buscar instrumentais de outros campos do conhecimento, para alimentar caminhos talvez inusitados; questionar as hierarquias; rever as margens onde as mulheres geralmente se encontram, no ato de produzir conhecimento.
\end{abstract}

Para Nancy Cardoso Pereira (2003, p. 196), a experiência

[...] é entendida como uma operação interna - expressão do ser ou da consciência - que projeta uma subjetividade na forma de identidade essencial, de caráter universal, acessível a todos/as.

Portanto, a experiência é desenvolvida na vida cotidiana de mulheres, é parte da subjetividadedecadaum/uma, eéessaexperiência que será base para a epistemologia feminista.

$\mathrm{Na}$ visão de Wanda Deifelt (2002) podemos considerar a experiência como base, pois o conhecimento feminista é forjado, dentre outros elementos, no bojo da experiência, pois ela produz conhecimento. Evidentemente, trata-se de um conhecimento marginalizado durante séculos, pois o conhecimento das mulheres, devido a sua exclusão do mundo público, foi tecido em espaços privados, logo, tidos como óbvios (EGGERT, 2003); espaços como o cotidiano artesanal e doméstico, consequentemente espaços invisíveis, como o privado, doméstico e artesanal. 


\section{A tecelagem manual}

A tecelagem é uma das formas mais antigas de artesanato presente nos dias atuais. Por volta de 5.000 a.C., a tecelagem era feita entrelaçando pequenos galhos e ramos para construir barreiras, escudos ou cestas. Teia de aranha e ninho de pássaros podem ter sido as fontes para a criação da tecelagem.

O primeiro tear foi, provavelmente, algo tão simples quanto uma estrutura vertical construída de galhos, no qual os fios eram pendurados e tencionados. De acordo com GilbertoLanzelotti(2009), outrosfioseram, então, entrelaçados manualmente, a um certo ângulo daqueles já tencionados, criando um tecido rústico. Aos gregos é atribuída a transferência do tear de posição vertical para a horizontal e, aos egípcios, a fixação dos fios de urdume em dois galhos a fim de poderem ser separados de modo a facilitar o entrelaçamento dos fios.

No Brasil, algumas nações indígenas conheciam e praticavam a tecelagem. Trabalhavam com algodão e trançados de palha. Com a chegada dos portugueses ao Brasil, a tecelagem passa a ser tramada no tear, artigo trazidos pelos portugueses. Em 1785, houve a proibição da confecção têxtil no Brasil.

Em 1785, a rainha Dona Maria I, a Louca, assinou um alvará mandando destruir todos os teares brasileiros. Dona Maria I fez isso pressionada pelas indústrias da Inglaterra, que exportava seus tecidos para o Brasil e não estavam dispostos a enfrentar concorrência da produção local (SENAC, 2002, p. 9).

A tecelagem sobrevive, então, na clandestinidade e nas regiões mais afastadas do Brasil, principalmente no interior dos estados de Minas Gerais e Rio Grande do Sul. Somente em 1809, a tecelagem sai da clandestinidade. Entretanto, no estado do Rio de Janeiro, sede da corte imperial, a tradição não conseguiu manter-se viva devido à facilidade de identificação dos teares e sua destruição.

\section{A tecelagem manual no Rio Grande do Sul}

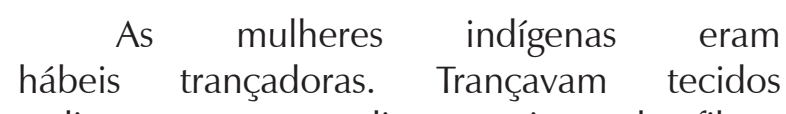
rudimentares com diversos tipos de fibras e algodão. Não sabemos se no Rio Grande do Sul elas usavam algum tipo de tear.

Com a chegada dos jesuítas, por volta do século XVII, estes ensinaram a índios e índias a fiação e a tecelagem em teares rústicos, aproveitando não só fibras e algodão, mas também a lã ovina. Barbosa Lessa (1980) aponta para os primeiros portugueses que desceram de São Paulo e estabeleceramse no Estado, como os introdutores do tear no Rio Grande do Sul. Quando descreve as suas primeiras moradias, o autor destaca a presença de instrumentos de tecelagem: "a um canto, bem resguardado, a roca e o fuso, para fazer fios de tecer" (LESSA, 1980, p. 37).

A técnica da tecelagem manual era executada quase exclusivamente pelas mulheres. Buscando-se pela origem da tecelagem, feita em teares neste Estado, encontramos, ainda na obra de Lessa (1980), a indicação da origem da tecelagem manual no município de Mostardas, no litoral. Surgindo com grandes expressões também em outros municípios, como Santa Vitória do Palmar, Jaguarão, Bagé, Lavras, Santana do Livramento e Uruguaiana, sendo estes últimos municípios da região da Campanha do Estado, tradicionalmente conhecida como produtora de rebanhos ovinos, o que naturalmente significava presença de grande quantidade de lã, matéria prima artesanal utilizada para fiação de fios para tecer.

Com os fios grossos, as mulheres teciam cobertores e ponchos. Assim, a fiação e a tecelagem manual faziam parte da rotina das mulheres dos primeiros portugueses, que se estabeleceram pouco antes do século XVIII. 
Como todo serviço doméstico e o cuidado dos filhos, também o provimento de vestimentas para toda a família dependia exclusivamente das mulheres.

A fixação da tecelagem doméstica no interior é uma continuidade dos diversos fazeres da casa, unindo-se aos trabalhos do campo, onde a mulher assume os cuidados da família, da cozinha e do artesanato de subsistência, onde se inclui a tecelagem pelo seu sentido primeiro de útil e de necessário (LODY, 1983, p.14).

O pouco que as mulheres gaúchas conseguiam produzir além de suas necessidades, como ponchos brancos com riscas pretas ou pardas, eram enviados principalmente a Porto Alegre e Rio Grande. Rau Lody (1983) lembra que os ponchos gaúchos eram artigos utilizados por gaúchos pobres, posto que os grandes fazendeiros usavam em suas viagens ponchos de lã industrializada.

Em 1824, os primeiros imigrantes alemães chegaram ao Rio Grande do Sul. Em sua maioria não eram agricultores, mas sim artesãos. Grande parte deles exercia algum ofício na Alemanha. Após terem passado os primeiros anos, os maiores obstáculos, tendo de se dedicar à agricultura de subsistência, estes alemães aos poucos foram retomando as atividades artesanais.

Vivendo em pobres ranchos, nem de móveis dispunham - sentavam-se em caixotes ou cepos - e haviam trocado a louça por porongos e cuias. Além da colheita agrícola, produziam farinha de mandioca, faziam o pão, a manteiga e a banha. Teciam seus próprios tecidos, rudimentares. Ainda que tivessem sido artesãos na Europa, aqui tinham de concentrar sua atividade na agricultura de subsistência (LESSA, 1980, p. 123).

O artesanato foi o elemento que fez com que esses imigrantes se fixassem na terra e expandissem o artesanato doméstico para o um nível de mercado. Desse modo, deram origem à indústria têxtil no Rio Grande do Sul.

Em 1874, a primeira indústria têxtil foi inaugurada no Estado, onde se fiava, tecia e tingia. No entanto, os alemães do interior continuavam a praticar o artesanato, bem como a tecelagem manual, pois as fábricas restringiam-se a algumas cidades, como Porto Alegre, Rio Grande e Pelotas.

Os imigrantes italianos também tiveram forte atuação no ramo têxtil. Estes também se dedicaram à tecelagem em maior escala, dando origem a pequenas fábricas têxteis, perdendo-se o caráter artesanal. Reichel (1978), em um estudo sobre o desenvolvimento da indústria do ramo de fiação e tecelagem no Estado, questiona-se quanto à origem dessas indústrias: teriam evoluído do artesanato ou surgido já estruturadas como indústrias?

A hipótese mais aceita pela autora é de que a tecelagem manual não concorreu com a indústria têxtil, ou seja, com as grandes fábricas de tecelagem. O processo manual atuava no interior enquanto as fábricas na cidade destinavam seus produtos à exportação.

Não pretendemos adentrar a esta discussão, pois, notavelmente, existem muitos antagonismos quanto à relação entre a tecelagem manual e industrial, no Estado. No entanto, é preciso lembrar que, com a Revolução Industrial, o artesanato foi gradativamente perdendo força e, no Rio Grande do Sul, certamente isso não foi diferente.

A artesã, professora e jornalista Naira Maria Ferreira, em depoimento ao jornal Profissão Artesão (2009), na ocasião da 19a Feira Latino Americana de Artesanato de Porto Alegre, lembra a Revolução Industrial como fator que restringiu o artesanato a algumas habilidades e o marginalizou por não pertencer à classe produtiva dominante. Também teria sido o Movimento Hippie, mais tarde, responsável pelo surgimento de grandes feiras de artesanato no centro do país: 
No Sul, os anos seguintes representam vitórias para os artesãos que, já tendo longa caminhada, documentação em carteira registrada, formou as primeiras feiras ao ar livre, organizadas e apoiadas pela sociedade que se rendia a resistência de pessoas que insistiam em ter seu próprio negócio produzir peças com qualidade e preço justo (PROFISSÃO ARTESÃO, 2009, não paginado).

Recorremos a alguns dados fornecidos pelo Ministério do Desenvolvimento, Indústria e Comércio Exterior, organizados juntamente com o Programa do Artesanato Brasileiro (PAB) e do Sistema de Informações Cadastrais do Artesanato Brasileiro (SICAB). Por meio destes dados, podemos constatar que mais da metade dos artesãos cadastrados são mulheres, cerca de $80 \%$ do número total. Quase $90 \%$ do total moram em zona urbana, bem como realizam suas atividades na própria residência, sendo que $52 \%$ dos artesãos e das artesãs recebem menos de um salário mínimo nacional e $42 \%$ recebem entre um a cinco salários, mas dificilmente ultrapassam do valor de um salário mínimo. Quanto à comercialização, 49\% é feita na própria residência do artesão ou da artesã, $22 \%$ em feiras e $14 \%$ em ruas ou praças.

Certamente esses números dão visibilidade à presença feminina em atividades artesanais, inclusive na tecelagem. Números que passam despercebidos aos olhos de muitos.

\section{Considerações Finais}

A tecelagem possui uma série de conhecimentos técnicos, realizados predominantemente por mulheres. Por essa razão, suspeitamos que esses saberes "perdem" muito de sua "técnica", "importância" e "conhecimento". O esvaziamento da potência desse saber tem vários motivos, entre eles, segundo Marcela Lagarde (2005), está o fato de a sociedade, em geral, acolher a ideia de que as mulheres têm como missão última e valor maior a maternidade, ou seja, tomar o cuidado para com os outros como tarefa básica. Deste modo, o trabalho principal da mulher para a sociedade compreende o doméstico e o privado.

$\mathrm{Na}$ escuta das tecelãs, identificamos depoimentos como: "isso é um trabalho, coisinha de mulheres para ajudar na renda familiar". Constatamos, porém, que a maioria dessas mulheres sustenta suas casas com as chamadas "coisinhas de mulheres". Segundo dados do Fórum Brasileiro de Economia Solidária (2007), 60\% das associadas são mulheres e, entre as suas atividades principais, estão a produção de peças de vestuário, alimentação e artesanato. Em nossa empiria, constatamos que as mulheres, muitas vezes, mantêm financeiramente sua família com a atividade da tecelagem. No entanto, verificamos também que não se reconhecem como tecelãs e muito menos são reconhecidas pelo seu trabalho.

O não reconhecimento destas mulheres e deseu trabalhotambém se evidencia na produção acadêmica. Tivemos dificuldades de encontrar bibliografia referente à História da Tecelagem, em especial do Rio Grande do Sul, onde o nosso projeto se efetua. Possivelmente, a falta de materiais indique que também a academia desvaloriza este campo de conhecimento, considerando-o "coisa de mulher", assim como as próprias tecelãs do grupo denunciam.

A valorização e a visibilidade do trabalho feminino é uma luta que está sendo travada, mas que ainda é longa, pois o trabalho da mulher é invisibilizado e desvalorizado, sobretudo quando se trata do trabalho doméstico e artesanal.

Entendemos que os processos não formais, logo, socialmente pouco reconhecidos, devem ser pauta da agenda educacional brasileira, contribuindo para o desvelamento das pedagogias invisibilizadas e clandestinas (STRECK, 2010; BRANDÃO; STRECK, 2006). Entre essas pedagogias, estão as ligadas ao artesanato, que pesquisamos. 


\section{Referências}

ALVES-MAZZOTTI, A. J.; GEWANDSZNAJDER, F. O método nas ciências naturais e sociais: pesquisa quantitativa e qualitativa. 2. ed. São Paulo: Pioneira, 1998.

BRANDÃO. C. R. A pergunta a várias mãos: a experiência da pesquisa no trabalho do educador. São Paulo: Cortez, 2003.

BRANDÃO. C. R; STRECK, D. Pesquisa participante. O saber da partilha. São Paulo: Ideias e Letras, 2006.

CASTRO, A. M. A.; BECKER, M. R.; EGGERT, E. Técnica e arte: trabalho artesanal produzido por mulheres e sua (in)visibilidade social. In: SIMPÓSIO INTERNACIONAL IHU: O (DES)GOVERNO BIOPOLÍTICO DA VIDA HUMANA, 11., 2010, São Leopoldo. Anais... São Leopoldo: IHU, 2010.

DEIFELT, W. O corpo e o cosmo. In: TIBURI, M.; MENEZES, M.; EGGERT, E. As mulheres e a filosofia. São Leopoldo: Editora da Unisinos, 2002.

DUARTE, R . Entrevistas em pesquisas qualitativas. Revista Educar, Curitiba, n. 24, p. 213-225, 2004

EGGERT, E. Educação popular e teologia das margens. São Leopoldo: Editora Sinodal, 2003.

. Trabalho manual e debate temático: tramando conhecimentos na simultaneidade. In: NEUENFELDT, E.; BERGSCH, K.; PARLOW, M. (Org.). In: Epistemologia, violência, sexualidade: olhares do II Congresso Latino-Americano de Gênero e Religião. São Leopoldo: Sinodal, 2008.

Narrar processos: tramas da violência doméstica e possibilidades para a educação. Florianópolis: Editora Mulheres, 2009.

- Trabalho precário X profissionalização de tecelãs: um desafio para a formação educacional no campo do artesanato gaúcho. CONGRESSO IBEROAMERICANO DE CIÊNCIA, TECNOLOGIA E GÊNERO, 8., Curitiba. Anais... Curitiba: UFTPR, 2010.

FREIRE, P. Pedagogia da autonomia: saberes necessários à prática educativa. 25.ed. São Paulo: Paz e Terra, 1999.

Pedagogia do oprimido. 45. ed. Rio de Janeiro: Paz e Terra, 2006.

GEBARA, I. Rompendo o silêncio: uma fenomenologia feminista do mal. São Paulo, Vozes, 2000.

. As epistemologias teológicas e suas consequências. In: NEUENFELDT, E.; BERGSCH, K.;

PARLOW, M. (Org.). Epistemologia, violência, sexualidade: olhares do II Congresso LatinoAmericano de Gênero e Religião. São Leopoldo: Sinodal, 2008.

JAPIASSÚ, H.; MARCONDES, D. Dicionário básico de filosofia. Rio de Janeiro: Jorge Zahar, 2006.

LANZELOTTI, G. História da tecelagem artesanal no Brasil. Disponível em: < http://guiadecorar. com.br/posts/visualiza/1493>. Acesso em: 10 out. 2009 
LAGARDE, M. Cautiverios de las mujeres: madresposas, monjas, putas, presas y locas. 4. ed., Ciudad del México: UNAM, 2005.

LESSA, L. C. B. Mão gaúcha: introdução ao artesanato sul-riograndense. Porto Alegre: Feplam, 1980.

LODY, R. G. Artesanato brasileiro: tecelagem. Rio de Janeiro: FUNARTE, 1983.

MAGNANI, J. G. C. Discurso e representação, ou de como os Baloma de Kiriwina podem reencarnarse nas atuais pesquisas. In: CARDOSO, R. A aventura antropológica: teoria e pesquisa. Rio de Janeiro: Paz e Terra, 1986.

PEREIRA, N. C.. Fragmentos e cacos de experiência: relações sociais de poder e gênero na teologia wesleyana. Revista Caminhando, Curitiba, v. 8, n. 2, 2003.

REICHEL, H. J. A indústria têxtil no Rio Grande do Sul (1910-1930). Porto Alegre: Mercado Aberto, 1978.

SAFFIOTI, H. I. B. Gênero, violência e patriarcado. São Paulo: Fundação Perseu Abramo, 2004.

SENAC. Fios e fibras: oficina de artesanato. Rio de Janeiro: Editora SENAC Nacional, 2002.

SCOTT, J. Experiência. In: SILVA, A. (Org.). Falas de gênero: teorias, análises, leituras. Florianópolis: Editora das Mulheres, 1999.

STRECK, D. Entre emancipação e regulação: (des)encontros sobre educação popular e movimentos sociais. Revista Brasileira de Educação, Rio de Janeiro, v. 15, n. 44, maio-ago. 2010.

TRIVIÑNOS, A. N. S. Introdução à pesquisa em ciências sociais: a pesquisa qualitativa em educação. São Paulo: Atlas, 1987.

Submetido em 9 de abril de 2012.

Aprovado em 2 de agosto de 2012. 